\title{
Pseudo-thermal anomalies
} in the shortwave infrared bands of the Himawari-8 $\mathrm{AHI}$ and their correction for volcano thermal observation

\author{
Takayuki Kaneko ${ }^{1 *} \mathbb{D}$, Atsushi Yasuda ${ }^{1}$, Yoshito Yoshizaki ${ }^{2}$, Kenji Takasaki ${ }^{3}$ and Yoshiaki Honda ${ }^{4}$
}

\begin{abstract}
Volcanic eruptions bring high-temperature gas or magma to the surface. Therefore, thermal observations of volcanic eruptions can be used to investigate the timeline of eruptive sequences. Eruptive activity includes processes that can change over short periods of time, which is sometimes related to the eruptive mode or the timing of its transitions. If we could observe short-term eruptive processes by detecting thermal changes, this would be beneficial for analyzing the eruptive sequence of volcanoes. Himawari-8 is a meteorological geostationary satellite operating above the equator at a longitude of $140.7^{\circ} \mathrm{E}$ and carrying a newly developed sensor, the Advanced Himawari Imager (AHI). With its improved performance, the Himawari-8 AHI enables the collection of high-frequency thermal observations that had never been obtained before. However, while observing volcanoes with the AHI, we noticed a frequent thermal anomaly in the nighttime 1.6- $\mu \mathrm{m}$ and $2.3-\mu \mathrm{m}$ images. Because this anomaly occurred regardless of volcanic activity, it was considered to be a pseudo-thermal anomaly. In-depth examination of the AHI observation data for several inactive volcanoes showed that the pseudo-thermal anomaly was often seen around the vernal and autumn eclipse periods, and its influence persisted for about 6 months of each year. Further, daily variation of the anomaly peaked when it was midnight in the areas around $140^{\circ}$ E. At this time and position, the AHI was facing the sun, suggesting that the anomaly was caused by stray light. We devised a correction method by assuming that the observed thermal radiance in a pixel consists of components from the radiating volcanic ground surface and stray light contamination. The latter can be estimated using values from nearby inactive pixels. Thus, the component from the radiating volcanic ground surface can be obtained by subtracting the estimated stray light from the observed thermal radiance. We evaluated the validity of this method using data from the 2017 Nishinoshima eruption and found that it satisfactorily removed the stray light component. An adoption of this correction allowed us to use all nighttime 1.6- $\mu \mathrm{m}$ and 2.3- $\mu \mathrm{m}$ images obtained by the AHI, half of which were formerly unusable due to the degradation caused by stray light.
\end{abstract}

Keywords: Himawari-8, AHI, Volcano, Stray light, Observation data correction, Thermal anomaly

\footnotetext{
${ }^{*}$ Correspondence: kaneko@eri.u-tokyo.ac.jp

1 Earthquake Research Institute, The University of Tokyo, 1-1-1 Yayoi,

Bunkyo-ku, Tokyo 113-0032, Japan

Full list of author information is available at the end of the article
} 


\section{Introduction}

Volcanic eruptions bring high-temperature gas or magma to the surface of the earth. Therefore, thermal observations of these eruptions can be used to investigate the timeline of eruptive sequences. Eruptive activity includes processes that can change over short periods of time, which is sometimes related to the eruptive mode or the timing of its transitions. Thus, thermal observation of short-term eruptive processes is very beneficial for analyzing the detailed eruptive sequence of volcanoes. Himawari-8 is a meteorological satellite operating at a geostationary position approximately $35,800 \mathrm{~km}$ above the equator at a longitude of $140.7^{\circ} \mathrm{E}$. It carries a newly developed sensor, the Advanced Himawari Imager (AHI), that operates in 16 spectral bands from the visible to thermal infrared (Japan Meteorological Agency 2015a; Okuyama et al. 2018). This instrument has great advantages for carrying out volcano thermal observations (Kaneko et al. 2018). The AHI has several shortwave to thermal infrared bands with improved spatial resolution of $2 \mathrm{~km}$ that can observe various scales of volcanic activity. In particular, the capability of capturing full-disk shortwave infrared images every 10 min enables us to observe shortterm high-temperature phenomena that have never been measured before. This is expected to provide valuable data for analyzing eruptive processes, such as the explosion of a lava plug in a conduit, a lava-dome collapse, or the exact timing of the onset and reactivation of lava effusion, as well as the precursory signals that precede these events (Kaneko et al. 2018). The real-time high performance of the AHI observations is also effective for obtaining information for unfolding disasters.

However, during our 2 years of observation using the Himawari-8 AHI in the Asia-Pacific region, we noticed that strange thermal anomalies were frequently observed in nighttime 1.6- $\mu \mathrm{m}$ and $2.3-\mu \mathrm{m}$ volcano images, regardless of whether the volcanoes were active. This strongly suggested that the thermal anomaly was not real but false, that is, a pseudo-thermal anomaly. Among the spectral bands of $\mathrm{AHI}$, the $1.6-\mu \mathrm{m}$ band is especially important for volcano thermal observation, as it is preferentially sensitive to high-temperature materials, such as magma exceeding several hundred degrees Celsius, while it is rarely affected by fluctuation of the background temperature (Wooster and Kaneko 1998; Kaneko et al. 2018). The 2.3- $\mu \mathrm{m}$ and 3.9- $\mu \mathrm{m}$ bands are also likely to be dominated by radiation from high-temperature surfaces, but surfaces at relatively lower temperatures will also show significant emissions within these spectral bands. These anomalies greatly degraded the usefulness of the valuable 1.6- $\mu \mathrm{m}$ band for volcano observation.

This study examined when and where this pseudothermal anomaly appeared and investigated its cause based on the data collected during past observations. Further, a simple correction method for this problem was devised and applied to an actual eruption to evaluate its effectiveness.

\section{Data and methods}

Himawari-8 AHI data are received at the Meteorological Satellite Center of the Japan Meteorological Agency and transferred to distribution servers at several institutes (Japan Meteorological Agency 2015a). We downloaded the AHI full-disk data from the science web cloud of the National Institute of Information and Communication Technology (NICT, sc-web.nict.go.jp/himawari/). Radiance values were obtained from the downloaded AHI data using the correction coefficients given in each file header (Japan Meteorological Agency 2015b), and we extracted each $101 \times 101$ pixel region that contained a volcano in its center using the geometric relationship defined by the normalized geostationary projection (Coordination Group for Meteorological Satellites 1999); these were the areas used for further analysis.

When measuring a radiating ground surface from space using nighttime shortwave infrared images, the spectral radiance $\left(R_{\lambda \text { obs }}\right.$, in $\left.\mathrm{W} \mathrm{m}^{-2} \mathrm{sr}^{-1} \mathrm{~m}^{-1}\right)$ recorded by the satellite can be described as follows:

$$
R_{\lambda \_ \text {obs }}=\frac{\tau_{\lambda} \varepsilon_{\lambda} C_{1} \lambda^{-5}}{\pi\left[\exp \left(\frac{C_{2}}{\lambda T}\right)-1\right]}
$$

where $C_{1}=3.742 \times 10^{-16} \mathrm{~W} \mathrm{~m} \mathrm{~m}^{-2}=2 \pi h c^{2}$ (where $h$ is Planck's constant and $c$ is the speed of light), $C_{2}=0.0144 \mathrm{~m} \mathrm{~K}=h c / k$ (where $k$ is Boltzmann's constant), $\lambda$ is the wavelength (in meters), $\varepsilon_{\lambda}$ is the emissivity of the radiating ground surface, $\tau_{\lambda}$ is the atmospheric transmittance, and $T$ (in kelvins) is temperature of the ground surface. From $R_{\lambda \_ \text {obs }}$, we can obtain $R_{\lambda}$, the atmospheric- and emissivity-corrected radiance (Harris 2013), from the radiating ground surface as shown below:

$$
R_{\lambda}=R_{\lambda \_ \text {obs }} /\left(\varepsilon_{\lambda} \tau_{\lambda}\right)
$$

In this study, the following parameters were adopted to examine the time-series variation of the thermal anomalies for each band (Kaneko et al. 2018). We calculated these thermal anomalies by examining each $7 \times 7$ pixel region with a volcano summit at its center (the "scan region"). The parameters $\mathrm{R} 1.6 \mathrm{Mx}$ and $\mathrm{R} 2.3 \mathrm{Mx}$ are the pixel values $\left(R_{\lambda}\right)$ that exhibit the maximum spectral radiance values (atmospheric- and emissivity-corrected) in the scan regions of the $1.6-\mu \mathrm{m}$ and $2.3-\mu \mathrm{m}$ images, respectively. Additionally, for reference, we used T3.9Mx and T11Mx, the pixel values that exhibit the maximum pixel-integrated temperatures (atmospheric- and 
emissivity-corrected) in the scan regions of the $3.9-\mu \mathrm{m}$ and $11-\mu \mathrm{m}$ images, respectively (temperatures were converted from $R_{\lambda}$ using Planck's equation). Details are described in Kaneko et al. (2018).

We chose six inactive volcanoes in the Asia-Pacific region to examine the annual and daily variations of the pseudo-thermal anomalies in the 1.6- $\mu \mathrm{m}$ and 2.3$\mu \mathrm{m}$ bands in 2017, as well as their spatial variations. All of the selected volcanoes were inactive during the observation periods (Smithsonian Institution, National Museum of Natural History, Global Volcanism Program), so no thermal anomalies should have been detected for any of them. We investigated volcanoes at various latitudes-high latitude: Avachinsky $\left(53.256^{\circ} \mathrm{N}, 158.836^{\circ} \mathrm{E}\right.$, $2717 \mathrm{~m}$ above sea level [ASL], Russia); middle latitude: Fuji $\left(35.361^{\circ} \mathrm{N}, 138.728^{\circ} \mathrm{E}, 3776 \mathrm{~m} \mathrm{ASL}\right.$, Japan) and
Izu-Oshima $\left(34.724^{\circ} \mathrm{N}, 139.394^{\circ} \mathrm{E}, 758 \mathrm{~m}\right.$ ASL, Japan); and low latitude: Telong $\left(4.769^{\circ} \mathrm{N}, 96.821^{\circ} \mathrm{E}, 2617 \mathrm{~m} \mathrm{ASL}\right.$, Indonesia), Long Island $\left(5.358^{\circ} \mathrm{S}, 147.12^{\circ} \mathrm{E}, 1280 \mathrm{~m} \mathrm{ASL}\right.$, Papua New Guinea), and Epi $\left(16.68^{\circ} \mathrm{S}, 168.37^{\circ} \mathrm{E}, 833 \mathrm{~m}\right.$ ASL, Vanuatu).

\section{Results}

Annual variation of pseudo-thermal anomalies during nighttime

To examine the annual variation of the pseudo-thermal anomaly, we selected the maximum values of $\mathrm{R} 1.6 \mathrm{Mx}$ and R2.3Mx each night and plotted them showing the time-series variation for 1 year (Fig. 1). In Fig. 1, conspicuous thermal anomalies can be recognized at all of the volcanoes. In most of the cases, they have large peaks both in the spring and autumn, shown as small peaks

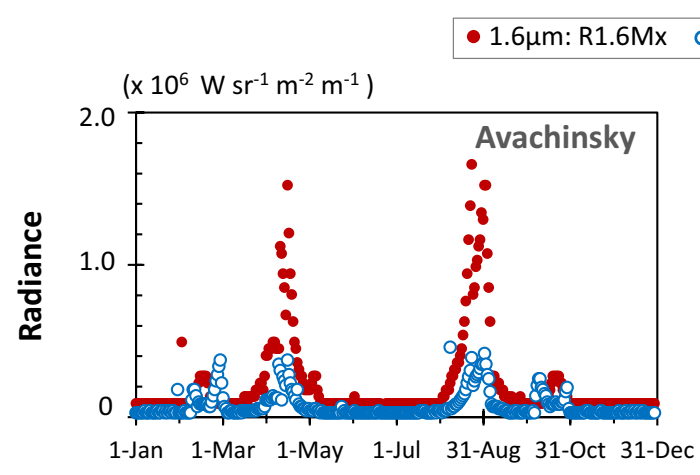

o $2.3 \mu \mathrm{m}: \mathrm{R} 2.3 \mathrm{Mx}$
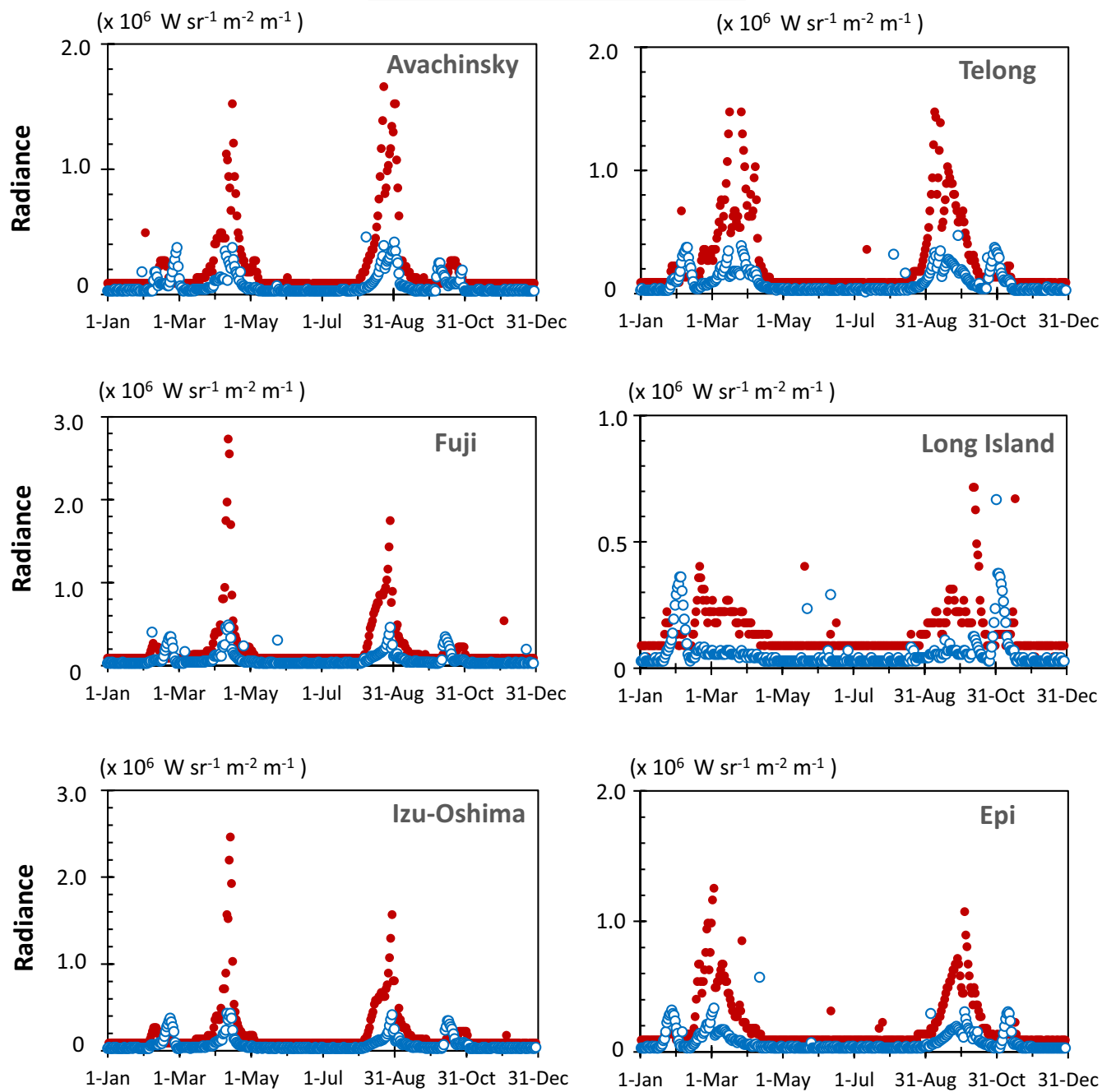

Fig. 1 Annual variation of the pseudo-thermal anomaly in the nighttime 1.6- $\mu \mathrm{m}$ and 2.3- $\mu \mathrm{m}$ images (2017) 
on the left- and right-hand sides, respectively (hereafter, these peaks are referred as the "spring anomaly peak" and "autumn anomaly peak," which also included "large peak" and "small peak," respectively). The locations of the apexes of the large peaks are about the same in both the 1.6- $\mu \mathrm{m}$ and 2.3- $\mu \mathrm{m}$ plots, although there are some differences in their pattern and height. In the middle to high latitudes, the spring anomaly peaks occurred between February and early May, and the autumn anomaly peaks occurred between August and October, while at low latitude, they occurred between mid-January and April and mid-August and mid-November. The levels of the pseudo-thermal anomalies were up to about $n \times 10^{6}$ and $n \times 10^{5} \mathrm{~W} \mathrm{~m}^{-2} \mathrm{sr}^{-1} \mathrm{~m}^{-1}$ in the $1.6-\mu \mathrm{m}$ and $2.3-\mu \mathrm{m}$ bands, respectively, which is comparable to the thermal anomaly observed during a medium-scale eruption (e.g., the 2015 Mt. Raung eruption, as reported by Kaneko et al. 2018). However, the pseudo-thermal anomaly is not seen in the 3.9- $\mu \mathrm{m}$ and $11-\mu \mathrm{m}$ bands.

\section{Daily variations of the pseudo-thermal anomaly}

Daily variation of the pseudo-thermal anomaly was examined by plotting the nighttime R1.6Mx and R2.3Mx values for each day in charts showing time-series variation (Fig. 2). Here, we chose days from September to early October 2017, close to the autumn anomaly peak, with the spring anomaly peak of Izu-Oshima also given for comparison. The peaks are nearly symmetrical and located between the hours of 12:00 and 17:00 coordinated universal time (UTC), with most peaks occurring between 13:00 and 16:00 UTC. Furthermore, at IzuOshima, the time of the peak observed on April 14near the spring anomaly peak-was the same as that on September 2, which suggests that the diurnal time of the peak is fixed at each volcano, regardless of the time of year. Volcanoes located in the western part of the study region (e.g., Telong) tended to have a peak sooner those in the eastern part (e.g., Epi).

\section{Discussion}

\section{Possible causes for pseudo-thermal anomaly}

The most useful clue for the cause of the anomaly is the timing of its appearance. The fact that the pseudo-thermal anomaly appears in the vernal and autumn equinox periods suggests that it is closely related to earth eclipse (Okuyama et al. 2018), that is, when a geostationary satellite, such as Himawari-8, enters the shadow of the earth (Fig. 3a). In the daily variations (Fig. 2), apexes of the peak of two Japanese volcanoes, Fuji and Izu-Oshimaat a longitude of about $140^{\circ} \mathrm{E}$-are located between 14:00 and 15:00 UTC, which is close to midnight in local time. This indicates that the imager of the Himawari-8 operating above the equator at $140.7^{\circ} \mathrm{E}$ is facing the sun
(Fig. 3a). During the earth eclipse, sunlight can enter the imager and generate parasitic light by diffusive scattering off the mirrors or reflection off non-optical parts of the telescope (e.g., baffles), which can reach the detector as stray light (European Organisation for the Exploitation of Meteorological Satellites). Shao et al. (2017) reported that a large amount of stray light contamination occurred in the full-disk imagery of the Himawari-8 AHI in visible to medium infrared bands over a few weeks around February and October to November.

Considering the points discussed above, we concluded that the pseudo-thermal anomaly peaks recognized in Figs. 1 and 2 originated from stray light. The results of our research show that those effects exert definite influence upon the nighttime images of the 1.6- $\mu \mathrm{m}$ and $2.3-\mu \mathrm{m}$ bands over very long periods during each yearabout 6 months, as suggested by Okuyama et al. (2018). Examples of the stray light that affects the AHI images are shown in Fig. 3b.

\section{Proposed correction method for stray light}

The characteristics of the time-series variations made it clear that we can observe volcanoes accurately using the 1.6- $\mu \mathrm{m}$ and 2.3- $\mu \mathrm{m}$ bands during the periods outside of the spring and autumn anomaly peaks (e.g., Kaneko et al. 2018). Further, even during the peak periods, we can theoretically use these two bands if we preferentially use the nighttime data taken at times other that the hours between 12:00 and 17:00 UTC. However, such limited datasets do not give us a full picture of eruption processes. To use the 1.6- $\mu \mathrm{m}$ and $2.3-\mu \mathrm{m}$ images to their full potential, we need accuracy every day at all times.

In this study, we devised a simple correction method that can remove the influence of stray light, which is thought to be superimposed onto terrestrial signals as additional radiance (Shao et al. 2017). This correction allows us to use all nighttime 1.6- $\mu \mathrm{m}$ and $2.3-\mu \mathrm{m}$ images obtained by the AHI, half of which were formerly unusable because of the degradation caused by stray light. Here, we assumed that $\mathrm{R} 1.6 \mathrm{Mx} \mathrm{x}_{\text {obs }}$ and $\mathrm{R} 2.3 \mathrm{Mx}$ _obs consist of the components from volcanic ground surface radiation, $\mathrm{R} 1.6 \mathrm{Mx} \mathrm{x}_{\text {vg_obs }}$ and $\mathrm{R} 2.3 \mathrm{Mx}$ _vg_obs, and stray light, R1.6_sl and R2.3_ss, which introduced contamination into each pixel, respectively, as follows:

$$
\begin{aligned}
& \mathrm{R} 1.6 \mathrm{Mx} \mathrm{x}_{-} \mathrm{obs}=\mathrm{R} 1.6 \mathrm{Mx} \mathrm{x}_{\text {_vg_obs }}+\mathrm{R} 1.6 \_\mathrm{sl} \\
& \mathrm{R} 2.3 \mathrm{Mx} \text { _obs }=\mathrm{R} 2.3 \mathrm{Mx} \mathrm{x}_{\text {_vg_obs }}+\mathrm{R} 2.3 \_\mathrm{sl}
\end{aligned}
$$

The parameters $\mathrm{R} 1.6_{\mathrm{sl}}$ and $\mathrm{R} 2.3_{\mathrm{sl}}$ are different at each volcano and vary with time. In fact, they decrease to zero for nearly half of the year.

Based on the results shown in Figs. 1 and 2, the scale of spatial variations of R1.6 ${ }_{s l}$ and R2.3 sl is inferred to be 
- 1.6 $\mu \mathrm{m}: \mathrm{R} 1.6 \mathrm{Mx}$ o $2.3 \mu \mathrm{m}: \mathrm{R} 2.3 \mathrm{Mx}$
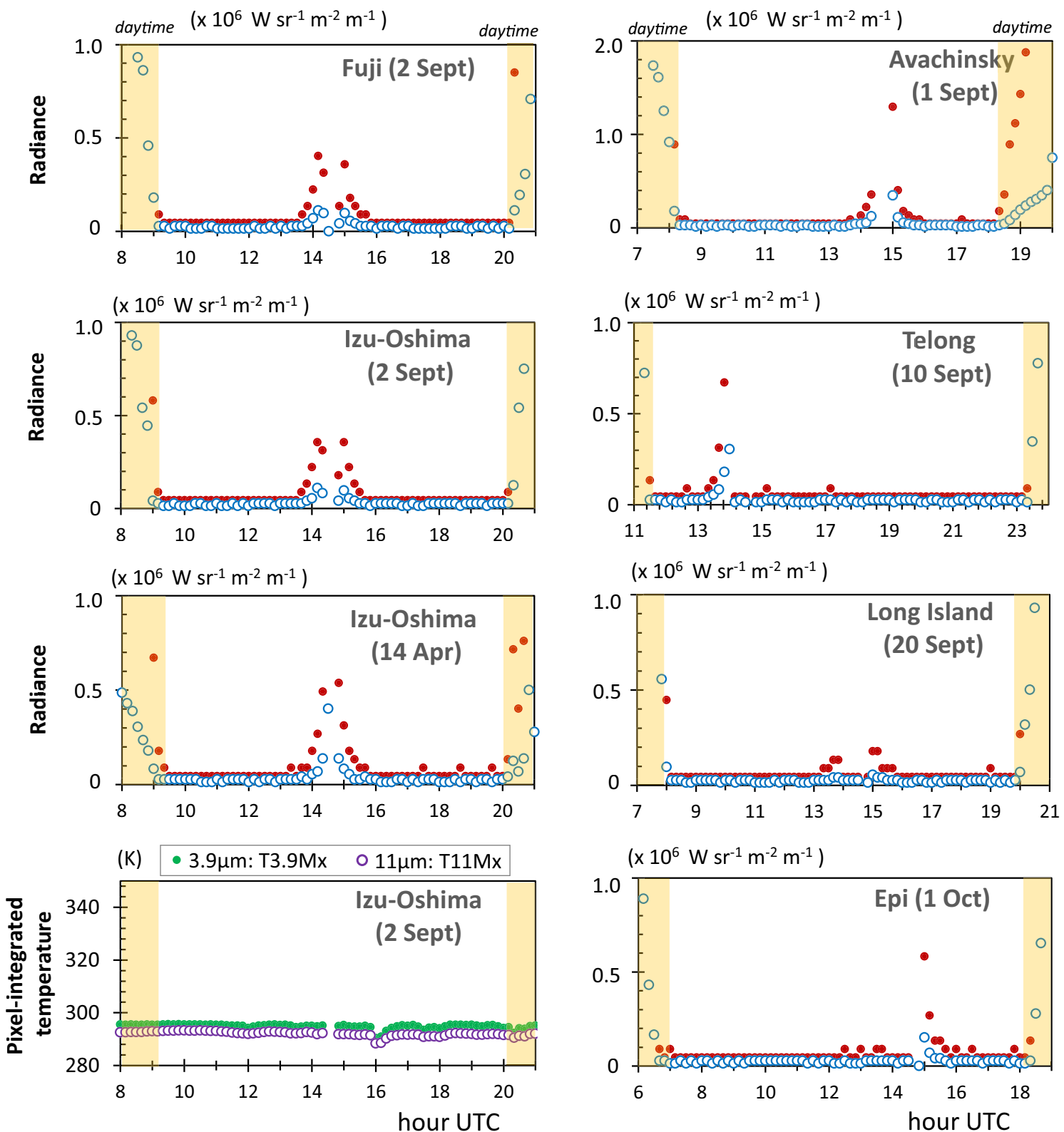

$\left(\times 10^{6} \mathrm{~W} \mathrm{sr}^{-1} \mathrm{~m}^{-2} \mathrm{~m}^{-1}\right)$

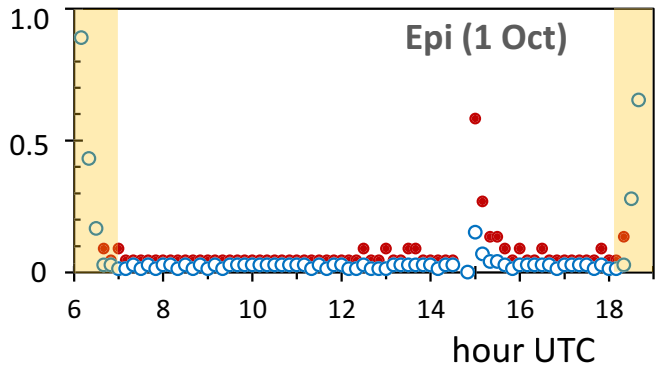

Fig. 2 Daily variation of the pseudo-thermal anomaly in the nighttime 1.6- $\mu \mathrm{m}$ and $2.3-\mu \mathrm{m}$ images (2017)

much broader than that of the area of the volcano. For example, volcanoes located in the same region, such as Fuji and Izu-Oshima, which are about $100 \mathrm{~km}$ apart, show approximately the same pattern (Fig. 2). This indicates that the values of R1.6 ${ }_{\text {sl }}$ and R2.3 ${ }_{\text {sl }}$ for the pixels of $\mathrm{R} 1.6 \mathrm{Mx}_{\text {obs }}$ and $\mathrm{R} 2.3 \mathrm{Mx}$ obs are about the same as those at pixels located several kilometers away.

Based on the above consideration, the values of R1.6 ${ }_{\text {sl }}$ and $\mathrm{R} 2.3_{\mathrm{sl}}$ can be estimated. Here, we tentatively estimated them from the average of the adjacent 14 pixels, located above and below (7 pixels each) the scan region consisting of $7 \times 7$ pixels in the same images as the $\mathrm{R} 1.6 \mathrm{Mx}$ obs and $\mathrm{R} 2.3 \mathrm{Mx}$ _obs$_{\text {, }}$, respectively. The R1.6_sl and R2.3_s obtained here also include the radiance values of the background. The values, however, are considered very low and nearly constant, as the temperature of the background is under the detection limit of the $1.6-\mu \mathrm{m}$ and $2.3-\mu \mathrm{m}$ bands of the AHI. They are estimated to be 


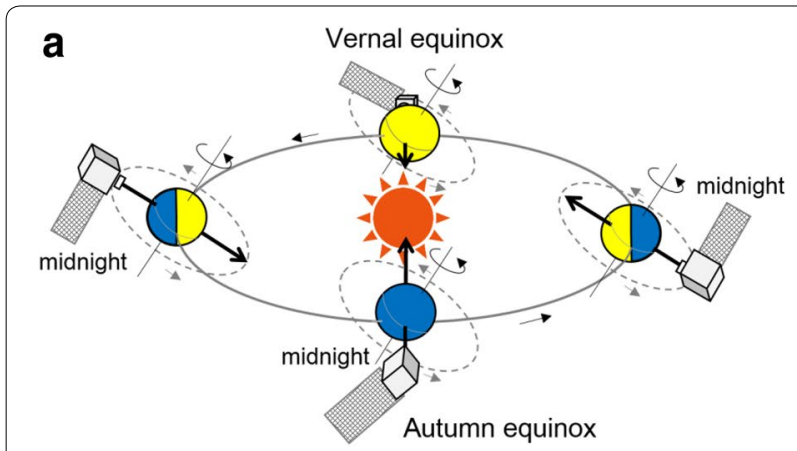

b

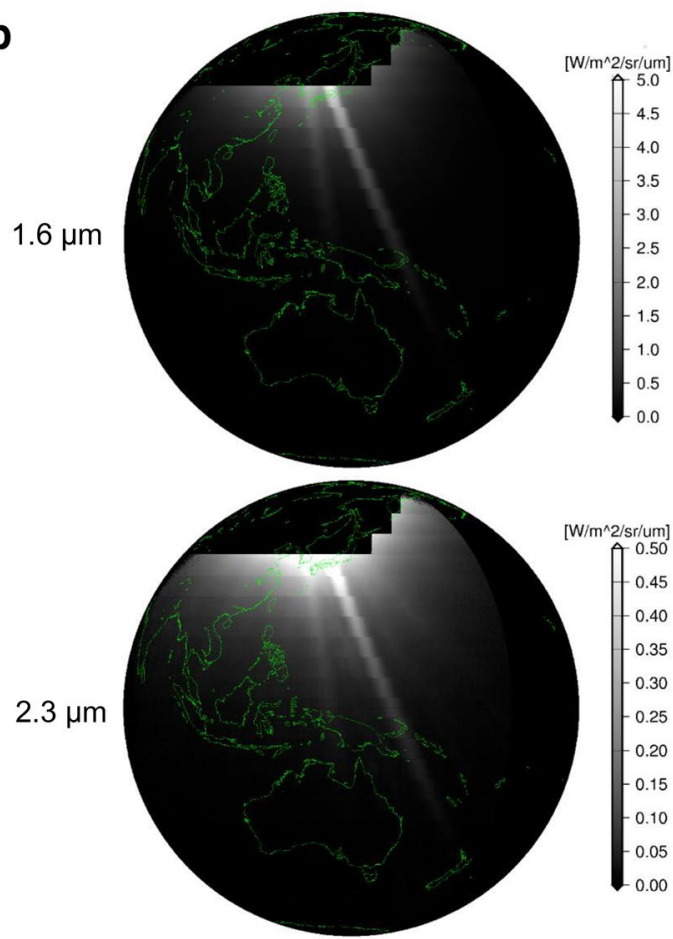

Fig. 3 a Schematic of relationship between orbital motions of Himawari-8 and the earth resulting in periodic earth eclipses. When Himawari-8 is located at the points where its orbital plane intersects that of the earth, all three bodies - Himawari-8, the earth, and the sun-are in the same plane. During the vernal and autumn eclipse periods, these conditions make the Himawari-8 imager face the sun, which causes an earth eclipse. b Stray light in the AHI images for 1.6- $\mu \mathrm{m}$ (upper) and 2.3- $\mu \mathrm{m}$ (lower) bands at 14:40 UTC on April 12, 2018. The scale represents radiance $\left(\mathrm{W} \mathrm{m}^{-2} \mathrm{sr}^{-1} \mu^{-1}\right)$

$0.016 \times 10^{6}$ and $0.045 \times 10^{5} \mathrm{~W} \mathrm{~m}^{-2} \mathrm{sr}^{-1} \mathrm{~m}^{-1}$, respectively, from the background pixels in the periods without influence of stray light. These R1.6 ${ }_{s l}$ and R2.3 ${ }_{s l}$ values were used for the correction.

We can calculate $\mathrm{R} 1.6 \mathrm{Mx}_{\text {_vg_obs }}$ and $\mathrm{R} 2.3 \mathrm{Mx}_{\text {_vg_obs }}$ by subtracting R1.6 sl and $\mathrm{R} 2.3_{\text {sl }}$ from $\mathrm{R} 1.6 \mathrm{Mx} \mathrm{obs}_{\text {obs }}$ and $\mathrm{R} 2.3 \mathrm{Mx}_{\text {obs }}$, respectively, as shown below:

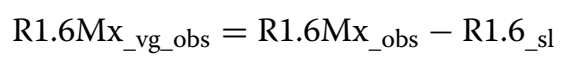

$$
\mathrm{R} 2.3 \mathrm{Mx} \mathrm{x}_{\text {vg_obs }}=\mathrm{R} 2.3 \mathrm{Mx} \mathrm{x}_{-} \mathrm{obs}-\mathrm{R} 2.3 \_\mathrm{sl}
$$

The atmospheric- and emissivity-corrected radiance from the volcanic ground surface, $\mathrm{R} 1.6 \mathrm{Mx}_{\mathrm{vg}}$ and $\mathrm{R} 2.3 \mathrm{Mx}_{\text {vgg }}$, are obtained using Eq. (2) from R1.6 Mx ${ }_{\text {vg_obs }}$ and $\mathrm{R} 2.3 \mathrm{Mx} \mathrm{v}_{\mathrm{vg} \_ \text {obs }}$, respectively, and can be used to evaluate eruption activity accurately.

\section{Application to an actual eruption: 2017 Nishinoshima eruption}

To examine the effectiveness and validity of this correction method for the pseudo-thermal anomaly, that is, stray light, we applied it to an actual eruption. We chose the Phase 2 activity of Nishinoshima that occurred in 2017 (analysis of the eruption processes will be reported in a separate paper). The parameters $\varepsilon_{\lambda}$ and $\tau_{\lambda}$ were assumed to be 1, as in Figs. 1 and 2. Nishinoshima is located $1000 \mathrm{~km}$ south of Tokyo, and this volcanic island, currently $2 \mathrm{~km}$ in diameter, was formed by eruptions during 2013-2015 (Maeno et al. 2016), known as Phase 1. On April 18, 2017 (JST), effusive activity began at the central cone and continued until the end of July (Maeno et al. 2018; Takeo et al. 2018). This is regarded as Phase 2.

Figure 4 shows the time-series variation of nighttime thermal anomalies between 8:24 and 20:24 UTC on April 9; this date is close to the apex of the spring anomaly peak but before the Phase 2 eruption. In the uncorrected timeseries variation, an anomalous peak appears between 13:32 and 15:36 UTC, but it disappears in the corrected time-series variation. The same is true for the $2.3-\mu \mathrm{m}$ anomaly. These results show that the pseudo-thermal anomaly can be satisfactorily removed with this method.

Figure 5 shows the time-series variation of the nighttime thermal anomalies during the 10 months from February to November 2017. The time-series variations of the uncorrected 1.6- $\mu \mathrm{m}$ band (Fig. 5a) show a small peak in February ("A"), a large peak from mid-March to late July ("B"), a peak from early August to late September ("C"), and a small peak in late October to early November ("D"). However, in the corrected time-series variation (Fig. 5b), the "B" anomaly between the mid-March and early April disappears. Also, the "A," "C," and "D" anomalies vanish completely. Only a partial "B" anomaly from mid-April to late July remains. Here, the portion remaining after correction for stray light should be the net volcanic thermal anomaly, and the removed portions are considered as the pseudo-thermal anomaly. Note that the time-series variation might be slightly affected by cloud cover, which lowered the radiance values, as we did not exclude images where the volcano was covered by clouds. However, the general features of the time-series variations are almost the same as those produced from images with little or no cloud cover. The same patterns hold true 

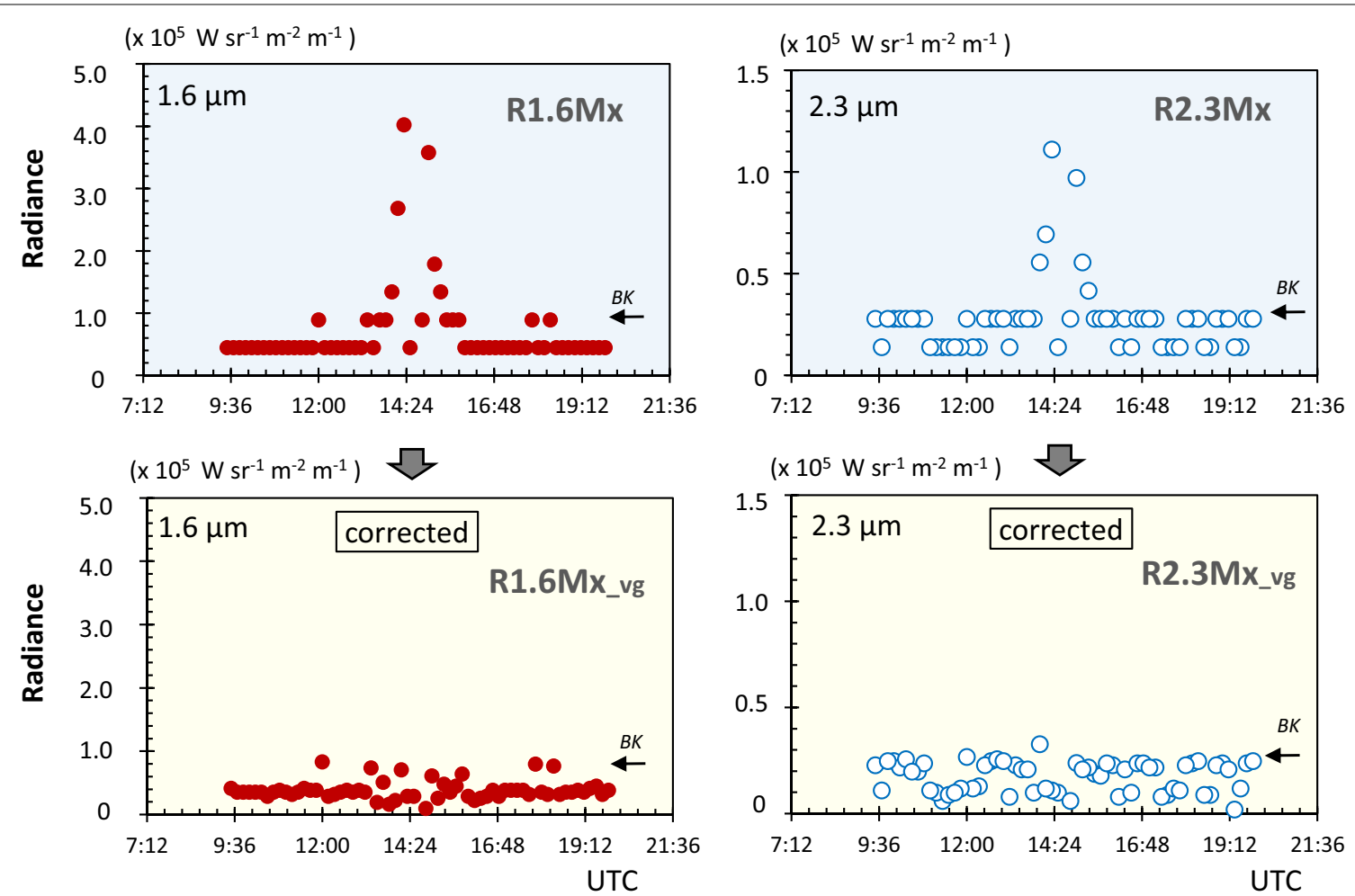

Fig. 4 Comparison between uncorrected and corrected data for stray light using the time-series variation of nighttime thermal anomalies in the 1.6- $\mu \mathrm{m}$ and 2.3- $\mu \mathrm{m}$ images between 8:24 and 20:24 UTC on April 9 (close to the apex of the spring anomaly peak but before the Phase 2 eruption)

for variation in the $2.3-\mu \mathrm{m}$ band (Fig. $5 \mathrm{c}, \mathrm{d}$ ). The timeseries variation of the thermal anomaly of the $3.9-\mu \mathrm{m}$ band (Fig. 5e), which is apparently not affected by stray light in our observations (e.g., Izu-Oshima in Fig. 2), is thought to reflect the actual variation of volcanic activity. This variation basically coincides with the corrected variations of $\mathrm{R} .6 \mathrm{Mx}_{\mathrm{vg}}$ and $\mathrm{R} 2.3 \mathrm{Mx_{ \text {vgg } }}$. This supports the validity of our correction method for stray light.

Shao et al. (2016) reported that stray light is greatest in the 3.9- $\mu \mathrm{m}$ band among the mid-infrared bands of the AHI; however, in our observations, we could not recognize a pseudo-thermal anomaly in the 3.9- $\mu \mathrm{m}$ band. The reason for this is that the amount of stray light at $3.9 \mu \mathrm{m}$ estimated as 3-4 K (Shao et al. 2016) is much lower than the level of the volcanic thermal anomaly seen in Fig. 5e.

\section{Concluding remarks}

The results obtained here can be summarized as follows:

1. When we observed volcanoes using the Himawari-8 AHI, we noticed that strange thermal anomalies occurred frequently and periodically in the nighttime 1.6- $\mu \mathrm{m}$ and 2.3- $\mu \mathrm{m}$ images, even at inactive volcanoes, while they did not appear in the $3.9-\mu \mathrm{m}$ and
11- $\mu \mathrm{m}$ images. These anomalies were considered to be pseudo-thermal anomalies.

2. The results of our investigations of data for several inactive volcanoes showed that the pseudo-thermal anomaly appeared around the vernal and autumn equinox periods. In the daily variations, the anomaly peaked when the areas around $140^{\circ} \mathrm{E}$ were imaged at about midnight (between 14:00 and 15:00 UTC), which corresponded to times when the Himawari- 8 imager was facing the sun. These facts suggested that the pseudo-thermal anomaly was caused by stray light, and it extensively contaminated the nighttime images in the $1.6-\mu \mathrm{m}$ and $2.3-\mu \mathrm{m}$ bands for about 6 months every year.

3. We devised a simple correction method, which assumed that the observed thermal radiance at a pixel actually consists of components from volcanic ground surface radiation and stray light that contaminated each pixel. The latter can be estimated by the pixel values of nearby inactive areas. We can obtain the component from the radiating volcanic ground surface by subtracting the estimated stray light from the observed thermal radiance.

4. We evaluated the validity of this method using an actual eruption. It was found that the component 


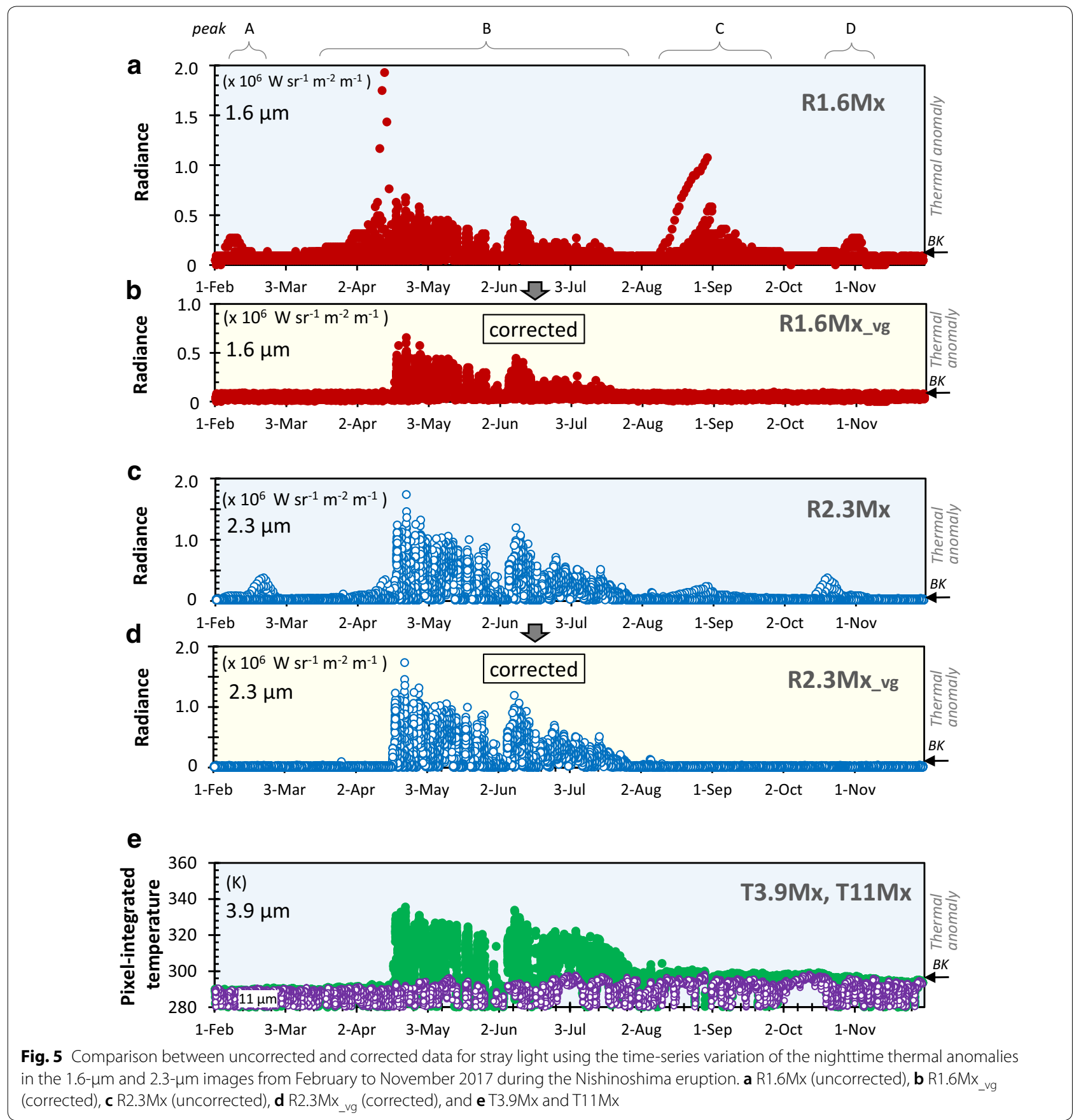

from stray light was satisfactorily removed from the thermal anomaly observed by the AHI in the 1.6- $\mu \mathrm{m}$ and $2.3-\mu \mathrm{m}$ bands, and we could successfully elicit the time-series variations of the net volcanic thermal anomaly.

By adopting this correction method, we were able to use almost all of the nighttime 1.6- $\mu \mathrm{m}$ and $2.3-\mu \mathrm{m}$ images of the AHI, half of which were formerly unusable due to the serious data degradation caused by stray light. These shortwave infrared bands are important for observing high-temperature phenomena related to magmatic activities, in particular for the 1.6- $\mu \mathrm{m}$ band, which is mostly unaffected by background temperature fluctuations. The results obtained here specifically increased the number of Himawari-8 AHI images available for observing high-temperature phenomena that change rapidly. This correction can be applied to AHI data from most of the 
volcanoes in the Asia-Pacific region, which allows us to retain one of the great advantages of the Himawari-8 AHI for volcano research.

\section{Authors' contributions}

TK, AY, and KT analyzed the Himawari-8 AHI images, and $Y Y$ and $Y H$ examined the effects of stray light on them. All authors read and approved the final manuscript.

\section{Author details}

${ }^{1}$ Earthquake Research Institute, The University of Tokyo, 1-1-1 Yayoi, Bunkyo-ku, Tokyo 113-0032, Japan. ${ }^{2}$ Meteorological Satellite Center, Japan Meteorological Agency, 3-235 Nakakiyoto, Kiyose, Tokyo 204-0012, Japan.

3 Japan Fisheries Research and Education Agency, 2-12-4 Fukuura, Kanazawa, Yokohama, Kanagawa 236-8648, Japan. ${ }^{4}$ Center for Environmental Remote Sensing, Chiba University, 1-33 Yayoi-cho, Inage-ku, Chiba-shi, Chiba 263-8522, Japan.

\section{Acknowledgements}

The Himawari-8 AHI data used in this study were collected, processed, and managed with the NICT science cloud led by K. Murata and were originally received by the Meteorological Research Center of the Japan Meteorological Agency. We thank K. Kajiwara of the Center for Environmental Remote Sensing, Chiba University, and $\mathrm{H}$. Murakami of JAXA/EORC for encouragement and helpful suggestions. We are also very grateful to two anonymous reviewers for their useful comments.

\section{Competing interests}

The authors declare that they have no competing interests.

\section{Availability of data and materials}

Not applicable.

\section{Funding}

This work was supported by an Earthquake and Volcano Hazards Observation and Research Program of the Ministry of Education, Culture, Sports, Science and Technology of Japan (No. 1520 to TK), GCOM/RA6 (PI No.118 to TK) from the Earth Observation Research Center of Japan Aerospace Exploration Agency (JAXA/EORC), and Grant-in-Aid for Scientific Research (A) from the Japan Society for the Promotion of Science (Kakenhi Grant 23241055 to TK).

\section{Publisher's Note}

Springer Nature remains neutral with regard to jurisdictional claims in published maps and institutional affiliations.

Received: 6 September 2018 Accepted: 25 October 2018

Published online: 06 November 2018

\section{References}

Coordination Group for Meteorological Satellites (1999) LRIT/HRIT Global Specification. https://www.cgms-info.org/documents/pdf_cgms_03.pdf. Accessed 20 Aug 2018

European Organisation for the Exploitation of Meteorological Satellites, Anomalies on meteosat image. www.eumetsat.int/website/home/Data/ ServiceStatus/AnomaliesonMeteosatlmages/index.html. Accessed 20 Aug 2018

Harris AJL (2013) Thermal remote sensing of active volcanoes, a user's manual. Cambridge University Press, Cambridge

Japan Meteorological Agency (2015a) Himawari-8/9 operational information. http://www.data.jma.go.jp/mscweb/en/operation8/. Accessed 20 Aug 2018

Japan Meteorological Agency (2015b) Himawari-8/9 Himawari standard data user's guide version 1.2. https://www.data.jma.go.jp/mscweb/en/himaw ari89/space_segment/hsd_sample/HS_D_users_guide_en_v12.pdf. Accessed 20 Aug 2018

Kaneko T, Takasaki K, Maeno F, Wooster MJ, Yasuda A (2018) Himawari-8 infrared observations of the June-August Mt Raung eruption, Indonesia. Earth Planets Space 70:89. https://doi.org/10.1186/s40623-018-0858-9

Maeno F, Nakada S, Kaneko T (2016) Morphological evolution of a new volcanic islet sustained by compound lava flows. Geology 44(4):259-262. https://doi.org/10.1130/G37461.1

Maeno F, Yasuda A, Nakano S, Yoshimoto M, Ohminato T, Watanabe A, Kaneko T, Nakada S, Takeo M (2018) Formation process of a new volcanic island at Nishinoshima, Ogasawara, Japan, inferred from eruptive products. J Adv Mar Sci Technol Soc 24:35-44 (in Japanese with English abstract)

Okuyama A, Takahashi M, Date K, Hosaka K, Murata H, Tabata T, Yoshino R (2018) Validation of Himawari-8/AHI radiometric calibration based on two years of in-orbit data. J Meteorol Soc Jpn 96B:91-109. https://doi. org/10.2151/jmsj.2018-033

Shao X, Wu X, Yu F (2016) Characterization of Himawari-8 AHI $3.9 \mu$ m channel stray light. In: Proceedings of SPIE 9972 Earth observing system XXI, 99720R-1, https://www.spiedigitallibrary.org/conference-proceedings-ofspie/9972/1/Characterization-of-Himawari-8-AHI-39-um-channel-stray -light/10.1117/12.2237052.short?SSO=1. Accessed 20 Aug 2018

Shao X, Wu X, Yu F (2017) Stray light performance comparison between Himawari-8 AHI and GOES-16 ABI. In: 2017 IEEE International geoscience and remote sensing symposium (IGARSS). https://ieeexplore.ieee.org/docum ent/8126951/. Accessed 20 Aug 2018

Smithsonian Institution, National Museum of Natural History, Global volcanism program. https://volcano.si.edu. Accessed 19 Oct 2018

Takeo M, Ohminato T, Maeno F, Shinohara M, Baba K, Watanabe A, Ichihara M, Nishida K, Kaneko T, Yasuda A, Sugioka H, Hamano Y, Tada N, Nakano S, Yoshimoto M, Takagi A, Nagaoka Y (2018) Geophysical observations and landing survey at Nishinoshima volcano. J Adv Mar Sci Technol Soc 24:45-56 (in Japanese with English abstract)

Wooster MJ, Kaneko T (1998) Satellite thermal analysis of lava dome effusion rate at Unzen volcano, Japan. J Geophys Res 103:20935-20947

\section{Submit your manuscript to a SpringerOpen ${ }^{\circ}$ journal and benefit from:}

- Convenient online submission

Rigorous peer review

- Open access: articles freely available online

- High visibility within the field

- Retaining the copyright to your article

Submit your next manuscript at springeropen.com 